\title{
Comparison of Preoperative Positron Emission Tomography/Computed Tomography with Panscopy and Ultrasound in Patients with Head and Neck Cancer
}

\author{
Amir M. Salehi $^{\mathrm{a}}$ Lena Norberg-Spaak ${ }^{\mathrm{a}}$ Simon Vallin $^{\mathrm{b}}$ Nicola Sgaramella $^{\mathrm{c}}$ \\ Karin Nylander ${ }^{c}$ \\ aDepartment of Otorhinolaryngology and Head and Neck Surgery, Umeå University, Umeå, Sweden; \\ ${ }^{b}$ Department of Statistics, Registercentrum Norr, Umeå University, Umeå, Sweden; 'Department of Medical \\ Biosciences, Umeå University, Umeå, Sweden
}

\section{Keywords}

Positron emission tomography/computed tomography . Panscopy · Head and neck tumor · Ultrasound · Computed tomography

\begin{abstract}
Introduction: To compare data from preoperative positron emission tomography/computed tomography (PET/CT) with results of panscopy with biopsy and ultrasound with fine needle aspiration cytology (US-FNAC) on the same patients. Methods: In this retrospective (2014-2016) study, we compared PET/CT results with the results from panscopy with biopsy and US-FNAC in patients suspected of head and neck malignancy treated at the University Hospital in Umeå, Sweden. Results: A 91.3\% concordance was seen between results from PET/CT and panscopy with biopsy, whereas between PET/CT and US-FNAC the concordance was $89.1 \%$. Conclusions: The present data show the usefulness of PET/ $\mathrm{CT}$ in the diagnosis of head and neck malignancies.
\end{abstract}

(c) 2020 The Author(s)

Published by S. Karger AG, Basel

\section{Introduction}

The standard technique for the diagnosis of head and neck tumors is clinical and endoscopic examination with biopsy [1]. A combination of positron emission tomography (PET) and computed tomography (CT) is increasingly used in head and neck oncology for the detection of unknown primary tumors, tumor staging, radiotherapy planning and post-treatment surveillance. PET alone provides poor anatomical information and is therefore linked to CT in order to obtain detailed information on the localization of a suspected oncological change [2-4].

The glucose analog ${ }^{18} \mathrm{~F}$-fluorodeoxyglucose (FDG) is widely used with PET/CT where it competes with glucose to enter into metabolically active cells. FDG is initially phosphorylated like glucose but cannot undergo further metabolism and thus gets trapped and accumulates within metabolically active tumor cells [2]. The technique of FDG PET is based on the detection of photons released during decay of FDG. Malignant cells show increased glycolysis leading to increased use of glucose. The effect of increased glycolysis in malignant cells was first described by Otto Warburg
C 2020 The Author(s)

Published by S. Karger AG, Basel

This is an Open Access article licensed under the Creative Commons Attribution-NonCommercial-4.0 International License (CC BY-NC) (http://www.karger.com/Services/OpenAccessLicense), applicable to the online version of the article only. Usage and distribution for commercial purposes requires written permission.
Amir M. Salehi

Department of Clinical Sciences, Umeå University

Building $6 \mathrm{M}$, 2nd floor

SE-90185 Umeå (Sweden)

whitecross@live.se 
in 1924 and is known as the Warburg effect. The most common way of expressing the FDG uptake is the standardized uptake value, representing the ratio of FDG concentration in a region of interest to its concentration in the whole body.

Due to its high specificity and sensitivity, FDG PET/ $\mathrm{CT}$ is the method of choice when dealing with metastatic disease in cervical lymph nodes. In the detection of head and neck cancer, an average sensitivity of $87-90 \%$ and a specificity of $80-93 \%$ has been reported for FDG PET/CT compared with a sensitivity of $61-97 \%$ and a specificity of $21-100 \%$ when using magnetic resonance imaging (MRI) or CT alone [5-8].

In Sweden, approximately 1,400 patients $(63 \%$ men, $37 \%$ women) are annually diagnosed with head and neck carcinoma, including different sites: lip, mouth, oropharynx, larynx, nose, sinus and salivary glands. In order to shorten the time between the first suspicion of cancer and the start of treatment, the so-called standardized treatment processes (STP) were introduced in Sweden in 2015 for selected cancer diagnoses, such as head and neck cancer. The model with STP had been initiated in Denmark years earlier [9]. Apart from shortening the time between the first suspicion of cancer to the start of treatment, STP are supposed to reduce regional differences, create a more equal healthcare with higher quality, achieve higher satisfaction among patients and improve cooperation between regional cancer centers.

A patient included in the STP is referred from the general practitioner to an ear, nose, throat (ENT) department due to suspicion of malignancy. The ENT specialist, after having examined the patient clinically, decides whether inclusion in the STP is indicated or not. Once included in the STP, PET/CT is performed, followed by ultrasound with fine needle aspiration cytology (US-FNAC), when there is suspicion of spread to lymph nodes and finally panscopy including biopsy and marking of tumor borders. Diagnosis, staging and treatment plan is then set at a joint multidisciplinary conference. According to STP, the time should not exceed 30 days from inclusion until start of surgical treatment and 38 days for the start of oncological or palliative treatment. After completing cancer treatment, with the exception of palliative treatment, patients are followed according to a 6-, 7- and 9-week program including CT at 6 weeks, control panscopy and US-FNAC at 7 weeks and, if indicated, neck dissection during the 9th week [9].

With the aim of assessing the usefulness of PET/CT in the diagnosis of patients with head and neck cancer, results from PET/CT scans were compared to results from panscopy including biopsy and US-FNAC from a group of patients affected by this disease.
Table 1. Characteristics of the patients

\begin{tabular}{lcc}
\hline Characteristic & Female & Male \\
\hline Patients, $n(\%)$ & $7(17 \%)$ & $35(83 \%)$ \\
Mean age, years (range) & $70.6(54-86)$ & $62.7(40-92)$ \\
Smoking & $4(57 \%)$ & $19(54 \%)$ \\
Tumor site & & \\
Hypopharynx, $n(\%)$ & - & $4(11 \%)$ \\
Oropharynx, $n(\%)$ & $7(100 \%)$ & $31(89 \%)$ \\
Tstage & & \\
T1/T2, $n(\%)$ & $4(57 \%)$ & $24(69 \%)$ \\
T3/T4, $n(\%)$ & $3(43 \%)$ & $10(29 \%)$ \\
$N$ stage & & \\
N0, $n(\%)$ & $3(43 \%)$ & $3(9 \%)$ \\
N1/N2, $n(\%)$ & $4(57 \%)$ & $30(86 \%)$ \\
N3, $n(\%)$ & - & $1(3 \%)$ \\
Metastasis & - & - \\
\hline
\end{tabular}

\section{Material and Methods}

Patients referred to the ENT clinic at Umeå University Hospital with suspicion of oro- and hypopharyngeal malignancy and later included in the STP during the period 2014-2016 were included in the study. Patient data were retrieved from the electronic files. The primary endpoint was to investigate the specificity (true-negative rate) and sensitivity (probability of detection/true-positive rate) of results from PET/CT in oro- and hypopharyngeal carcinomas.

Forty-two patients were included in the study, 35 men (83\%) with a mean age of 62.7 years and 7 women $(17 \%)$ with a mean age of 70.6 years. In women, all tumors were located in the oropharynx, while men had hypopharyngeal (11\%) oropharyngeal (89\%) tumors. Smoking data was only available from 23 patients. Thirtyfour patients were p16-positive and 8 p16-negative. The majority of patients were T1/T2 and N1/N2 (Table 1). Levels of C-reactive protein were within the normal range for all patients included.

Patients were investigated using PET/CT at the Umeå University Hospital's Nuclear Medical Department followed by panscopy with biopsy and US-FNAC. Results from all examinations were discussed after 7 days at a multidisciplinary conference comprising ENT specialists, oncologists, a pathologist, an oral and plastic surgeon and via video link also doctors from the referring hospitals.

Statistical Analysis

Statistical analysis was performed using IBM SPSS statistics software, version 25.0.

\section{Results}

Of the 42 patients, 1 patient did not have any detectable cervical lymph nodes, and no fine needle aspiration was performed. Of the 42 biopsies, 41 were positive and 1 negative for tumor when analyzing the biopsies microscopically. Looking at PET/CT 41 were positive and 1 
Table 2. Contingency table

\begin{tabular}{llll}
\hline PET/CT & PANSC & \multicolumn{2}{c}{ Total } \\
\cline { 2 - 3 } & positive & negative & \\
\hline Positive & 40 & 1 & 41 \\
Negative & 1 & 0 & 1 \\
\hline Total & 41 & 1 & 42 \\
\hline
\end{tabular}

negative for tumor presence. There was, however, not a $100 \%$ overlap, as the tumor sample being negative in the histological analysis was positive when using PET/CT, and the sample being negative with PET/CT showed tumor at histological analysis. All in all, the concordance between the methods was $91.3 \%$ (Table 2).

In the 41 cytological smears taken, 30 showed tumor content, whereas 11 were negative. Of the 30 cytologically positive smears, PET/CT had judged 29 as positive. Interestingly, all 11 smears judged as negative at cytological analysis had been classified as tumor positive with PET/CT. The concordance between the two methods was $89.1 \%$ (Table 3 ).

\section{Discussion}

${ }^{18} \mathrm{~F}-\mathrm{FDG}$ PET/CT is increasingly being used in the diagnosis of distant metastases, second primaries, recurrent/residual conditions, carcinoma of unknown primary (CUP) and guidance in head and neck cancer due to its high sensitivity (90\%) and specificity $(94 \%)[5,10]$. The disadvantage of this technique is false-positive results caused by for example inflammatory changes. False-negative results can also occur in lymph nodes that are less than $10 \mathrm{~mm}$ and in patients in whom the definition of vascularization is variable, that is the distribution of vascularity is variable [5].

In the present study, the concordance between results from PET/CT and panscopy with biopsy was 91.3\%, where 1 patient being classified as tumor positive with PET/CT turned out to lack tumor tissue in his/her biopsy. A negative result in a biopsy, however, does not exclude the presence of a tumor, instead it emphasizes the importance of representative precise biopsies. From this aspect, with one PET/CT-positive patient being negative when taking a biopsy, in most instances it calls for new biopsies.

Factors such as limited tumor volume, vascularization of the area, FDG malfunction and human error could also
Table 3. Contingency table

\begin{tabular}{|c|c|c|c|}
\hline \multirow[t]{2}{*}{$\mathrm{PET} / \mathrm{CT}$} & \multicolumn{2}{|c|}{ US-FNAC } & \multirow[t]{2}{*}{ Total } \\
\hline & positive & negative & \\
\hline Positive & 29 & 11 & 40 \\
\hline Negative & 1 & 0 & 1 \\
\hline Total & 30 & 11 & 41 \\
\hline
\end{tabular}

play a role in explaining why a PET/CT-positive sample shows negative results in the biopsy.

Looking at PET/CT compared to US-FNAC, 11 of the 40 cases classified as positive with PET/CT did not show any tumor cells in the FNAC analysis. As the diameter of the needles used in fine needle aspiration is very limited, good results with FNAC are dependent on either tumor tissue or a skilled and experienced cytologist/radiologist with the ability to pinpoint the exact tumor area.

Apart from ${ }^{18} \mathrm{~F}$-FDG PET/CT there are other positron

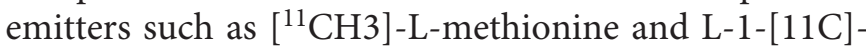
tyrosine with greater potential in distinguishing malignant and inflammatory tissue [11-13]. But because $\left[{ }^{11} \mathrm{CH} 3\right]-\mathrm{L}-m e t h i o n i n e$ accumulates in the salivary glands, tumor detection in these regions may be difficult [14]. ${ }^{18} \mathrm{~F}$-fluorodeoxyglucose PET/CT is widely used at the ENT department at the University Hospital in Umeå, Sweden, as part of the preoperative treatment planning for head and neck carcinomas. This retrospective study showed almost $91.3 \%$ concordance between PET/CT and the control panscopy with biopsy. In the PET/CT and the control US-FNAC group, there was $89.1 \%$ concordance.

The imaging tools available today advance and perfect the clinicians' ability to diagnose and determine the extent of the primary tumor and the possible accompanying adenopathy $[15,16]$. The advantages of ultrasound are accessibility and cost efficiency. Ultrasound detection of lymph node metastases in the cervical region has an accuracy of $70-89 \%[17,18]$, but with this method not all areas, i.e., hypopharynx, skull base, or nasopharynx, are reachable. The visualization depth is $4-6 \mathrm{~cm}$, and results are dependent on the knowledge and experience of the operator [19].

CT gives a great overview and better resolution/delineation than PET and ultrasound, and is also more accessible and less expensive than PET. It is the modality of choice when it comes to examining deep tissue [20]. However, false-negative results occur in cases where there are limited morphological changes such as in carcinomas with superficial spread or primary glottic carcinomas, but also when 
distinguishing scarred/irradiated tissue from disease [5]. Compared to MRI (specificity 79\%), CT (specificity 85\%) has a higher specificity when it comes to distinguishing between malignant and inflammatory tissue [21].

In conclusion, the present data clearly show the usefulness of PET/CT in the diagnosis of head and neck malignancies, whereas further studies are required to assess the adequacy of its use in the detection of spread to lymph nodes.

\section{Statement of Ethics}

Ethical approval: All procedures performed in studies involving human participants were in accordance with the ethical standards of the institutional and/or national research committee and with the 1964 Helsinki Declaration and its later amendments or comparable ethical standards. This study was approved by the local ethics committee (Regionala Etikprövningsnämnden, Umeå: No. 2018-105-31M). In this retrospective study, data was collected from the records and thus no patient consent was required.

\section{Conflict of Interest Statement}

There were none reported from any of the authors.

\section{Funding Sources}

The Swedish Cancer Society [contract number 1805 42] funded this project.

\section{Author Contributions}

Amir Salehi: planned the study, analyzed data and wrote the manuscript; Lena Norberg Spaak: planned the study and wrote the manuscript; Simon Vallin: analyzed the data; Nicola Sgaramella: analyzed the data and wrote the manuscript; Karin Nylander: wrote the manuscript. All authors read and approved the submitted version of the manuscript.

\section{References}

1 Vokes EE, Weichselbaum RR, Lippman SM, Hong WK. Head and neck cancer. N Engl J Med. 1993;328(3):184-94.

2 Fletcher JW, Djulbegovic B, Soares HP, Siegel BA, Lowe VJ, Lyman GH, et al. Recommendations on the use of $18 \mathrm{~F}$-FDG PET in oncology. J Nucl Med. 2008;49(3):480-508.

3 Al-Ibraheem A, Buck A, Krause BJ, Scheidhauer K, Schwaiger M. Clinical Applications of FDG PET and PET/CT in Head and Neck Cancer. J Oncol. 2009;2009 208725.

4 Gordin ADM, Israel O. Hybrid imaging of head and neck malignancies. Hybrid PET/CT and SPECT/CT imaging. New York: Springer; 2010; p. 137-71.

5 Di Martino E, Nowak B, Hassan HA, Hausmann R, Adam G, Buell U, et al. Diagnosis and staging of head and neck cancer: a comparison of modern imaging modalities (positron emission tomography, computed tomography, color-coded duplex sonography) with panendoscopic and histopathologic findings. Arch Otolaryngol Head Neck Surg. 2000;126(12):1457-61.

6 Schmid DT, Stoeckli SJ, Bandhauer F, Huguenin $\mathrm{P}$, Schmid S, von Schulthess GK, et al. Impact of positron emission tomography on the initial staging and therapy in locoregional advanced squamous cell carcinoma of the head and neck. Laryngoscope. 2003;113(5): 888-91.
7 Schwartz DL, Rajendran J, Yueh B, Coltrera M, Anzai Y, Krohn K, et al. Staging of head and neck squamous cell cancer with extended-field FDG-PET. Arch Otolaryngol Head Neck Surg. 2003;129(11):1173-8.

8 Schöder H, Yeung HW. Positron emission imaging of head and neck cancer, including thyroid carcinoma. Semin Nucl Med. Med2004;34(3):180-97.

9 OW. Standardiserad vårdförlopp i cancervården. 2016.

10 Laubenbacher C, Saumweber D, WagnerManslau C, Kau RJ, Herz M, Avril N, et al. Comparison of fluorine-18-fluorodeoxyglucose PET, MRI and endoscopy for staging head and neck squamous-cell carcinomas. J Nucl Med. 1995;36(10):1747-57.

11 Leskinen-Kallio S, Någren K, Lehikoinen $P$, Ruotsalainen U, Joensuu H. Uptake of 11Cmethionine in breast cancer studied by PET. An association with the size of S-phase fraction. Br J Cancer. 1991;64(6):1121-4.

12 Kubota R, Kubota K, Yamada S, Tada M, Takahashi T, Iwata R, et al. Methionine uptake by tumor tissue: a microautoradiographic comparison with FDG. J Nucl Med. 1995; 36(3):484-92

13 Braams JW, Pruim J, Nikkels PG, Roodenburg JL, Vaalburg W, Vermey A. Nodal spread of squamous cell carcinoma of the oral cavity detected with PET-tyrosine, MRI and CT. J Nucl Med. 1996;37(6):897-901.
14 Leskinen-Kallio S, Någren $\mathrm{K}$, Lehikoinen $\mathrm{P}$, Ruotsalainen U, Teräs M, Joensuu H. Carbon-11-methionine and PET is an effective method to image head and neck cancer. J Nucl Med. 1992;33(5):691-5.

15 Dooms GC, Hricak H, Crooks LE, Higgins CB. Magnetic resonance imaging of the lymph nodes: comparison with CT. Radiology. 1984;153(3):719-28.

16 Mafee MF, Campos M, Raju S, Samett E, Mohamadi H, Sadighi S, et al. Head and neck: high field magnetic resonance imaging versus computed tomography. Otolaryngol Clin North Am. 1988;21(3):513-46.

17 van den Brekel MW, Stel HV, Castelijns JA, Nauta JJ, van der Waal I, Valk J, et al. Cervical lymph node metastasis: assessment of radiologic criteria. Radiology. 1981;177(2):379-84.

18 Gritzmann N, Czembriek H, Hajek P, et al. Sonographie bei cervikalen Lymphknotenmetastasen. Radiologie. 1987;27:118-22.

19 Brinkmann G, Brix F, Sonography AB. CT, $M R$ in soft part growths in the head and neck region. Röntgenblätter. 1990;43:58-64.

20 Archer CR, Yeager VL. Computed tomography of laryngeal cancer with histopathological correlation. Laryngoscope. 1982;92(10 Pt 1):1173-80.

21 Adams S, Baum RP, Stuckensen T, Bitter K, Hör G. Prospective comparison of 18F-FDG PET with conventional imaging modalities (CT, MRI, US) in lymph node staging of head and neck cancer. Eur J Nucl Med. 1998;25(9): 1255-60. 